\title{
La presencia del estoicismo en la filosofía de Spinoza: naturalismo estoico y spinoziano
}

\author{
(The presence of Stoicism in the Spinoza's \\ philosophy: Stoic and Spinozian naturalism)
}

\author{
Inmaculada Hoyos SÁNCHEZ
}

Recibido: 27 de marzo de 2012

Aceptado: 20 de noviembre de 2012

\section{Resumen}

El propósito de este trabajo es mostrar, por una parte, que el estoicismo es una de las fuentes principales del naturalismo spinoziano, y por otra, que hay diferencias en el alcance y nivel de desarrollo de ambos naturalismos. Se trata, pues, de determinar qué afinidades y diferencias hay en sus conceptos de naturaleza y qué implicaciones tienen éstas en el ámbito práctico. Y ello, sobre todo, atendiendo a la diferente concepción de las pasiones que ambos mantuvieron.

Palabras clave: Spinoza, estoicismo, naturalismo, ontología, ética, pasiones.

\begin{abstract}
The aim of this paper is to show, on the one hand, that Stoicism is one of the main sources of Spinozian naturalism, and on the other hand, that there are differences in the scope and in the level of development of both naturalisms. Therefore, it deals with determining what are the similarities and differences in their concepts of Nature and what are the implications on a practical level. And all this, taking mainly into consideration the different conception of the passions that they maintained.
\end{abstract}

Keywords: Spinoza, Stoicism, naturalism, ontology, ethics, passions. 


\section{Introducción: estoicismo y anti-estoicismo en la filosofía de Spinoza}

La interpretación de la que parte este estudio es aquella según la cual la filosofía de Spinoza es una filosofía naturalista porque concibe lo real como Naturaleza, $\mathrm{y}$, en esa medida, se opone a toda otra concepción de lo real como algo sobrenatural, trascendente a la naturaleza misma ${ }^{1}$. El naturalismo es una ontología de la inmanencia, y, tal y como señala Deleuze, es una ontología de la inmanencia que lucha contra las mistificaciones que, sean del signo que sean, crean falsos infinitos y se apoyan en la desazón del alma y la tristeza para asentar su poder ${ }^{2}$.

El propósito del presente estudio se inscribe, pues, en la labor de especificación de las fuentes antiguas del naturalismo spinoziano. Y ello porque comprender el origen del naturalismo de Spinoza redunda en un conocimiento más preciso de las características singulares de éste y de otros naturalismos que ha habido en la historia de la filosofía, así como en una mayor comprensión de las relaciones entre la Antigüedad y la Modernidad filosóficas. Pues bien, la tesis que aquí se mantiene es que el estoicismo es una, y quizá la principal, de las fuentes antiguas del planteamiento naturalista spinoziano. Las referencias explícitas que se hallan en la obra de Spinoza a pensadores estoicos no son demasiado numerosas, pero indican que Spinoza tenía cierto conocimiento del estoicismo ${ }^{3}$. Spinoza conoce algunos de sus tópicos fundamentales y discute explícita o implícitamente con los estoicos cuestiones tan importantes como las que atañen a la ética de las pasiones. Así lo hace con Séneca, pues es el estoicismo tardío el que más y mejor conoció Spinoza ${ }^{4}$. Aunque también es probable que conociera la versión del estoicismo antiguo proporcionada por Diógenes Laercio 5 . Y así, ciertos tópicos del estoicismo más ortodoxo, como por ejemplo, el ideal del sabio insensible.

También hay que señalar, en este sentido, que casi todos los intérpretes que han realizado un estudio comparativo entre el pensamiento estoico y el spinoziano han

\footnotetext{
1 Tomo esta definición de naturalismo de Ferrater Mora (1994).

2 Cf. Deleuze (1971, pp. 354-355).

${ }^{3}$ Las tres referencias explícitas fundamentales son: la crítica a la concepción estoica del alma y de su inmortalidad que aparece en Tratado de la Reforma del Entendimiento, 774 (Geb. II, 28) (111); la crítica a la concepción estoica del suicidio del sabio en Ética[E], IV, 20, schol. (Geb. II, 224-225) (309310); y, especialmente, la crítica a la concepción y terapia estoica de las pasiones que aparece en $\mathrm{E}, \mathrm{V}$, Praef. (Geb. II, 277-278) (383-384). Las referencias a la obra de Spinoza llevan entre paréntesis la indicación Carl Gebhardt (Geb.), tomo y página correspondiente a la edición Spinoza. Opera (1972). A continuación, también entre paréntesis, aparece la página correspondiente a la edición castellana de las obras de Spinoza.

4 En este sentido, Proietti (1989, p. 54) indica que Las Epistolas morales están presentes en la biblioteca de Spinoza en la edición de Lipsio de 1649 y en la traducción holandesa de 1654 preparada por J. H. Glazemaker.

5 Scottlaender (1986, p. 5) señala que Spinoza puede haber tenido acceso al libro VII de Diógenes Laercio en una edición bilingüe de 1615, y, de este modo, pudo haber conocido la doctrina de Crisipo.
} 
apostado por la misma metodología para abordar este tema. De este modo, se inclinan por comparar las similitudes y diferencias conceptuales de una y otra filosofía. Pero no sólo en la metodología hay bastante acuerdo. La mayoría de los intérpretes opta por mostrar las afinidades y divergencias entre el estoicismo y la filosofía de Spinoza sin decantarse tajantemente a favor o en contra del carácter estoico de esta última. Hay ciertos momentos estoicos en la filosofía de Spinoza que conviven con otros que no lo son (Matheron 1999); Spinoza aparece como un quasi-estoico en ciertos temas, pero rechaza puntos fundamentales del estoicismo en otras materias (Long 2003). Es cierto, sin embargo, que según la interpretación, hay cierta tendencia a poner mayor énfasis en las afinidades o en las divergencias entre uno y otro. Ciertos intérpretes otorgan un mayor peso a las diferencias (Sévérac, 1996); otros, en cambio, subrayan los parecidos (Carnois, 1980). Y hay quienes se arriesgan a definirse claramente en una u otra dirección (James, 1993). La tesis de James, en este sentido, es que la Ética puede entenderse como un trabajo de reconstrucción del estoicismo6.

La interpretación que aquí se propone de la filosofía de Spinoza está en sintonía con aquella que subraya las afinidades y divergencias que existen entre ésta y el pensamiento estoico. De este modo, la tesis de James nos parece desmesurada. Spinoza no pretendió nunca restaurar el estoicismo. Es cierto que hay una serie de tesis compartidas por una y otra filosofía que permiten concluir, como se tratará de mostrar, que en ambos hay una actitud naturalista común. Sin embargo, el naturalismo de Spinoza es mucho más coherente y está más desarrollado que el naturalismo estoico. Y ello se refleja, sobre todo, en la muy distinta concepción y terapia de las pasiones que ambos propusieron. Ésta es la doble tesis fundamental que aquí quiere ponerse de manifiesto. No obstante, para ello hay que comenzar analizando las respectivas premisas ontológicas de las que parte la reflexión spinoziana y la estoica.

\section{Ontología: Natura estoica y spinoziana}

\section{a) Ontología y ética}

Uno de los aspectos en los que Spinoza parece retomar el planteamiento estoico estriba en la vinculación tan estrecha que para ambos hay entre ontología y ética. Tanto en una como en otra, los dos conceptos fundamentales del estoicismo son el lógos (razón) y la phýsis (naturaleza) ${ }^{7}$. La naturaleza como un todo está informada por la razón y por ello el estoicismo puede unificar todos los aspectos de la filoso-

${ }^{6}$ Cf. James (1993, p. 291)

7 Cf. Long (1977, p. 123). 
fía e ir de la ontología a la ética y viceversa. También podría decirse de la filosofía de Spinoza que sus dos conceptos fundamentales son la ratio y la Natura. Ahora bien, tal y como veremos, Spinoza no puede transitar tan fácilmente como el estoico desde la Naturaleza hasta lo bueno. Y tampoco es exactamente cierto que la razón sea un concepto fundamental de la ontología de Spinoza como lo es para el estoico. En la filosofía de Spinoza, hay una esfera de la Naturaleza, la que corresponde a la Natura naturata finita, que da cabida a algo que no es contrario por definición a la razón, pero tampoco es exactamente la razón, esto es, la pasión. Spinoza señala, en el prefacio del libro III de su Ética, que las pasiones no son opuestas a la razón, sino que son cosas naturales que pueden avenirse con ella. De este modo, la afinidad aparente esconde diferencias.

\section{b) Deus sive Natura}

En cuanto a las tesis propiamente ontológicas, también los estoicos, como el propio Spinoza, tienen un sistema monista y determinista basado en la proposición de que todo suceso debe tener una causa ${ }^{8}$. Sin embargo, el tópico que comparten el estoicismo y el spinozismo, que tiene más relevancia para la tesis que aquí queremos respaldar, tiene que ver precisamente con el naturalismo de ambos. La importante fórmula spinozina Deus sive natura tiene un antecedente en el estoicismo. En este sentido, el trabajo de J. Lagrée sobre el uso de ciertos términos estoicos en el Tratado teológico-político [TTP] es muy significativo.

La tesis de Lagrée es que la filosofía de Spinoza no es una prolongación o reelaboración del estoicismo. Sin embargo, en el Tratado teológico-político Spinoza toma cierto vocabulario estoico tradicional, sobre todo, aquel que procede de la tradición retórica de Cicerón y del Séneca moralista de la Epístolas morales a Lucilio, para respaldar la orientación racionalista de la filosofía en la que Spinoza cree. El uso de este vocabulario desempeña en la obra de Spinoza una doble función. Por una parte, tiene un papel demarcativo, esto es, excluye las bagatelas y fantasías aristotélicas y platónicas. Por otra parte, tiene una función estratégica, esto es, asegura de manera más dulce el paso del discurso imaginativo religioso tradicional al discurso filosófico racional que rechaza la distinción entre lo natural y lo sobrenatural y afirma la inteligibilidad de lo real. Sin embargo, Lagrée precisa que Spinoza no toma los conceptos propiamente estoicos cuando usa su vocabulario, sino que se sirve estratégicamente de esta terminología, de manera muy hábil, para lograr que los lectores libres de prejuicios, pero todavía no auténticamente filósofos, acepten sus propias tesis9.

\footnotetext{
8 Casi toda la bibliografía secundaria coincide en señalar esta afinidad entre Spinoza y el estoicismo. Cf James (1993), Matheron (1999), Pohlenz (2005), Scottlaender (1986).

${ }^{9}$ Cf. Lagrée (2004, p. 95).
} 
Y precisamente una de estas tesis que Spinoza quiere mostrar con ayuda del estoicismo se refiere a la asimilación de Dios y la Naturaleza. Esta asimilación, que en el Tratado teológico-político pasa por la asimilación de la potencia de la naturaleza con la potencia de Dios, se realiza, según Lagrée, por la vía de la cita implícita de la Historia natural de Plinio 10; aunque la fórmula Deus sive Natura es considerada, desde la presentación de la física del estoicismo por parte de Justo Lipsio, como una fórmula auténticamente estoica, y también se atribuye a Séneca, en concreto, a sus Cuestiones Naturales. Como ya se ha observado antes, Lagrée encuentra en este préstamo del estoicismo una estrategia de rechazo de lo sobrenatural a partir de la identificación estoica entre Dios y la naturaleza. El estoicismo ignora lo sobrenatural y para él no existe nada fuera de este mundo. ${ }^{11}$ La ontología estoica, como la spinoziana, es, pues, naturalista.

\section{c) Finalidad y bien en la naturaleza}

Ahora bien, a partir de esta afinidad en el punto de partida, es decir, del monismo y el determinismo causal, y la asimilación de Dios y la Naturaleza, empiezan a perfilarse diferencias importantes entre el planteamiento estoico y el spinoziano. Estas dos diferencias se corresponden con dos tesis estoicas que Spinoza combate, aunque no explícitamente contra el estoicismo, en el apéndice del libro I de su Ética, a saber, la tesis de que la Naturaleza responde a causas finales y que es, en sí misma, amable o buena. Tal y como explica Long, una providencia divina como la que sostuvieron los estoicos presupone una capacidad en Dios o en la Naturaleza para producir obras buenas. Los estoicos sostenían que éste es el mejor de los mundos posibles. Hasta en sus más nobles cimas, en los escritos de Epicteto o Marco Aurelio, hay algo escalofriante y sorprendente en la fe estoica de que a la postre todo acabará bien 12 .

10 "Pero los mayores consuelos para la naturaleza imperfecta del hombre son que ni siquiera Dios lo pueda todo, pues no puede darse muerte aunque quisiera (que es el mayor don que concedió al hombre en tantas calamidades de la vida), ni premiar a los mortales con la eternidad, ni resucitar a los muertos, ni hacer que quien vivió no hubiera vivido, que quien obtuvo honores no los hubiera obtenido, que tampoco tenga ningún derecho sobre el pasado, salvo el del olvido, y, por estrechar nuestra relación con Dios también con argumentos más amenos, que no pueda lograr que dos por diez no sean veinte y muchas otras cosas por el estilo. Por todo ello se confirma indudablemente el poder de la naturaleza y que eso es lo que llamamos Dios." (Plinio El Viejo, Historia natural, II, 5, 27). El texto en el que Spinoza afirma que "el poder de la naturaleza es el mismo poder de Dios" es del TTP, cap.XVI (Geb. III, 189) (335).

11 Cf. Lagrée (2004, p.85) A la identificación de Dios y de la Naturaleza como tópico compartido por el estoicismo y el spinozismo se refieren también Matheron (1999, pp. 302-303) y Long (2003, pp. 10 y 13$)$.

12 Cf. Long (1977, p. 168). 
Ahora bien, no hay una fe tal en la filosofía de Spinoza. Es cierto que Spinoza se refiere a lo largo de la Ética, y en otras obras, a la perfección de la Naturaleza. Sin embargo, el concepto de perfección sólo tiene un sentido ontológico y no moral en la filosofía de Spinoza cuando se refiere a la naturaleza en sí misma. La Naturaleza es perfecta porque no hay nada más real, es decir, con más potencia o poder de existir que la Sustancia o Dios. La perfección, referida a la Natura naturans, es sinónimo de realidad. 13 Ahora bien, la perfección en sentido moral, es decir, el bien, no se refiere nunca a las cosas o la naturaleza consideradas en sí mismas. Sin embargo, los estoicos entienden esta perfección metafísica en un sentido moral también. El mundo responde al plan o designio divino y, en este sentido, es bueno y amable. Sin embargo, no es así en la filosofía de Spinoza. El mundo no responde a fines, $y$, en este sentido, no es ni bueno ni malo. Tampoco la perfección de la Natura naturata tiene el sentido moral que le otorgan los estoicos, pues no hay una intervención divina sobre ella en el sentido en el que la entienden los estoicos. La Natura naturans se expresa inmanentemente en la Natura naturata, pero no imponiendo fines, ni disponiendo así un orden amable y bueno en ella. También en el caso de la Natura naturata, la perfección es sinónimo de realidad. ${ }^{14}$ Sin embargo, si entendemos la perfección en un sentido moral, esto es, lo bueno, como también lo malo, "tampoco son otra cosa - objeta Spinoza- que modos de imaginar, por los que la imaginación es afectada de diversas maneras, $\mathrm{y}$, sin embargo, son consideradas por los ignorantes como si fuesen los principales atributos de las cosas."15 Lo bueno y lo malo son conceptos relativos, esto es, atañen a la relación que se establece entre el hombre y la naturaleza, pero no se refieren nunca a la naturaleza misma, ni a la Natura naturans ni a la Natura naturata.

Una consecuencia de esta atribución de finalidad y de virtud a la Naturaleza es, tal y como señala críticamente Spinoza, el antropomorfismo divino. En este sentido, A. Long señala que otro de los aspectos en los que Spinoza y el estoicismo son polos opuestos tiene que ver con la racionalidad de Dios o la Naturaleza. Spinoza insiste en que si Dios tuviese entendimiento, sería completamente diferente del nuestro, porque somos sólo modos finitos de Dios. ${ }^{16}$ Los estoicos, sin embargo, suponen que, aunque Dios no es antropomórfico, la mente divina tienen las mismas facultades que tienen los seres humanos, y que un ser humano podría, en teoría, igualar lo divino en conocimiento y excelencia. ${ }^{17} \mathrm{Si}$ tenemos en cuenta que para la

13 Cf. E, II, def. VI (Geb. II, 85) (111).

14 Cf. E, I, 11, schol. (Geb. II, 54) (59).

15 E, I, Appendix (Geb. II, 82) (103).

16 Cf. E, I, 17, schol. (Geb. II, 62) (70).

17 "Pues bien, me parece que, quien no se percata de que el propio espíritu y la mente del hombre, su razón, su capacidad para deliberar y su sabiduría, sean llevado hasta la perfección gracias a un divino cuidado, carece precisamente de tales cosas. (...) De ahí se deduce qué gran poder entraña la sabiduría y en qué consiste; ni siquiera en la divinidad hay cosa alguna más eminente que ella." (Cicerón, Sobre la naturaleza de los dioses, II, 59, 147). 
interpretación tradicional los fundamentos de la ética estoica se hallan en la teleología y la racionalidad de la naturaleza cósmica o Dios, entonces las diferencias entre Spinoza y el estoicismo son más profundas de lo que en principio puede parecer. ${ }^{18}$ La clave reside en el distinto concepto de naturaleza que tienen ambos. También estas diferencias afectan al ámbito de la ética. En este campo, sin embargo, es en el que la influencia del estoicismo en la Modernidad, y en concreto, en la filosofía de Spinoza es mayor y, por tanto, donde cobra mayor plausibilidad nuestra hipótesis de que el estoicismo es una de las fuentes principales del naturalismo spinoziano.

\section{Conatus y officium: fundamentos de la ética estoica y spinoziana}

Tal y como se ha puesto de manifiesto en el apartado dedicado a la ontología, los dos conceptos fundamentales del estoicismo son la naturaleza y la razón. Esto también vale para su ética. La Naturaleza es criterio de valor en la medida en que el acuerdo o el desacuerdo con ella conforman lo bueno y lo malo. Así, Crisipo escribía que no hay vía posible o más acomodada para abordar el tema de los bienes y los males, las virtudes y la felicidad, que partiendo de la naturaleza universal y el gobierno del universo ${ }^{19}$.

Estrechamente relacionado con el concepto de naturaleza, está el concepto de conatus, central tanto en la ética estoica como en la spinoziana. La ética se despliega a partir del conatus. Desde el impulso primario a perseverar en el ser hay que llegar hasta la razón, la virtud y la felicidad; términos que son idénticos para el estoicismo y para el spinozismo.

El punto de partida de la ética estoica se halla en el impulso primario (conatus) de toda criatura recién nacida a conservarse a sí misma y rehuir lo que es dañoso hasta el límite de su poder. Cicerón merece ser citado en este punto.

"Dicen los estoicos - afirma- que es estimable (creo que podemos llamarlo así) lo que o por sí mismo está de acuerdo con la naturaleza o produce algo que lo está, de suerte que es digno de ser elegido porque tiene cierto valor merecedor de estima, que ellos llaman axía; por el contrario, dicen que no merece estima lo opuesto a lo anterior. Establecidos, pues, los impulsos primarios de tal manera que lo que está de acuerdo con la naturaleza debe ser apetecido por sí mismo y lo opuesto debe ser rechazado, el primer deber [officium] (así traduzco el griego kathékon) es conservarse en el estado natural. (...) La primera inclinación del hombre es hacia las cosas

\footnotetext{
18 Cf. Long (2003, p. 15).

19 Cf. Long, (1977, p. 176). Para esta cuestión también puede verse Plutarco, De Stoicorum repugnantiis, 1035c (Stoicorum Veterum Fragmenta [SVF] III, 68) = On Stoic self-contradictions 1035c-d [Trad. Long/ Sedley 1988, I 60A].
} 
que están de acuerdo con la naturaleza; pero tan pronto como adquiere entendimiento, o más bien, noción, llamada por ellos énnoia, y ve en lo que debe hacer un orden y, por decirlo así, armonía, la estima mucho más que todas las cosas que amó al principio, y, así, por el conocimiento y la razón comprende que es allí donde reside aquel supremo bien del hombre que debe ser alabado y deseado por sí mismo.”20

En este texto, según señala A. Long, se encuentran las doctrinas fundamentales de la ética estoica. A partir de aquí se imponen varias reflexiones o preguntas. En primer lugar, ¿lo que es natural para los seres vivos no racionales también lo es para los hombres? Lo virtuoso, ¿es lo mismo para ambos? La respuesta a esta pregunta es compleja. Cada una de las etapas trazadas por Cicerón asigna a los seres humanos un deber que le es idóneo en un período determinado de su desarrollo. Cosas que son idóneas en una primera etapa, no cesan de ser tales ulteriormente. Mas su relación con el deber del hombre cambia según él cambia. Cada nueva etapa añade algo que modifica el deber precedente inmediato. La meta del progreso es la vida de acuerdo con la naturaleza humana madura, es decir, la vida gobernada por principios racionales, que están en completa armonía con la racionalidad, metas y proceso de la Naturaleza universal. Cuando un hombre alcanza la racionalidad, esta modificación de su naturaleza dicta un nuevo modo de comportamiento apropiado. El deber de un hombre es ahora cumplir actos apropiados, cuyo punto de partida no es el mero impulso o instinto, sino la razón. Un acto apropiado se define como aquel que la razón insta a realizar. 21

Y es precisamente en la propia razón sólida, firme y resuelta en lo que consiste la virtud ${ }^{22}$. La virtud es una especie de conocimiento. Virtud es también el fin que la Naturaleza ha fijado para el hombre. En tercer lugar, en este actuar según la razón y la virtud reside la felicidad 23 .

De este modo, podemos decir del planteamiento ético estoico lo mismo que podemos afirmar de la ética de Spinoza, a saber, que establece una ecuación entre razón, virtud y felicidad, como es propia del planteamiento clásico, pero su planteamiento es más original porque añade dos términos nuevos, la naturaleza y el conatus, a esa ecuación. En principio esto pone de manifiesto que la ética de Spinoza

20 Cf. Cicerón, Del supremo bien y del supremo mal, III, 6, 20-21.

${ }^{21}$ Cf. Long (1977, p. 187). En este sentido, Diógenes Laercio [D.L.] recoge el testimonio de Zenón y Crisipo y dice, tras mostrar que la naturaleza ha dotado a todo ser vivo del impulso a conservarse, que "a los racionales les ha sido dada la razón en una preeminencia más perfecta, y para éstos el vivir de acuerdo con la razón rectamente resulta lo acorde con la naturaleza. Pues ésta es o como un artesano que supervisa el instinto. (D. L, VII, 86).

22 "Por eso Zenón fue el primero, en su Sobre la naturaleza del hombre, en decir que el fin es vivir acordadamente con la naturaleza, que es precisamente vivir de acuerdo con la virtud". (D. L, VII, 87). 23 "Virtue is a consistent character, choiceworthy for its own sake and not from fear or hope or anything external. Hapiness consists in virtue since virtue is a soul which has been fashioned to achieve consistency in the whole of life." D. L., VII, 89 (SVF III, 39) = [Trad. Long/Sedley 1988, I 61 A]. 
podría ser una ética estoica casi de término a término. Y ello porque también la ética spinoziana mantiene, en primer lugar, que el fundamento primero de la ética se halla en el conatus; en segundo lugar, que su fundamento último se halla en el actuar guiados por la razón y así en el cumplimiento de nuestro deber u officium; y en tercer lugar, que la razón es idéntica con la virtud y con la felicidad.

En cuanto a lo primero, y tal y como señala B. Carnois, es posible que Spinoza se haya inspirado en la tradición estoica al concebir el conatus como aquel esfuerzo por el que el hombre busca necesariamente aquello que sirve a su propia conservación, esto es, lo útil24. Que el conatus es también el punto de partida de la ética de Spinoza se prueba con la proposición 20 del libro IV de la Ética. "Cuanto más se esfuerza cada cual en buscar su utilidad, esto es, en conservar su ser, y cuanto más lo consigue, tanto más dotado de virtud está; y, al contrario, en tanto que descuida la conservación de su utilidad -esto es, de su ser-, en esa medida es impotente." 25 Spinoza se sitúa contra todos aquellos que creen que el principio de la búsqueda de la propia utilidad es el fundamento de inmoralidad y no de la moralidad como él pretende y demuestra. Y esto es un signo claro de naturalismo porque tras esa búsqueda de utilidad lo que se halla es el conatus, esto es, la naturaleza.

En segundo lugar, también podemos encontrar en la obra de Spinoza el uso del término estoico officium que aparece en el texto de Cicerón antes citado. Así, en el capítulo XXXII del apéndice del libro IV de la Ética, Spinoza señala que no tenemos la potestad absoluta de amoldar según nuestra conveniencia las cosas exteriores a nosotros. "Sin embargo, - escribe- sobrellevamos con serenidad los acontecimientos contrarios a las exigencias de la regla de nuestra utilidad, si somos conscientes de haber cumplido con nuestro deber (officium)." 26 Tal y como ha puesto de manifiesto A. Matheron, el término officium que emplea Spinoza aquí es aquel por el cual Cicerón traduce el término griego kathékon, que designa en los estoicos la acción conveniente. Que Spinoza ha tenido aquí la intención expresa de usar una palabra del vocabulario técnico estoico, es lo que indica el hecho de que la expresión suo officio fungi es muy rara en él. En este capítulo XXXII esta expresión designa el cumplimiento de lo que nos ha dictado nuestra razón. En otro pasaje del libro IV este mismo cumplimiento lo vincula Spinoza a lo que él llama "acción recta", lo que esta vez corresponde al katórthōma estoico 27.

En tercer lugar, la razón, la virtud y la felicidad son términos idénticos en la ética de Spinoza, de modo que ésta está de acuerdo en términos generales con el

${ }^{24}$ Cf. Carnois (1980, p. 258). Esta tesis no es solo propia del estoicismo antiguo sino también del más tardío de Epicteto. Así podemos leer en su Manual: "En efecto, todo ser animado tiende por naturaleza a rehuir y evitar las cosas que parecen nocivas y sus causas, y, por el contrario, a buscar y apegarse a las provechosas y sus causas." (Manual, 31).

25 E, IV, 20 (Geb. II, 224) (309).

26 E, IV, Appendix, cap. XXXII (Geb. II, 276) (379).

27 Cf. Matheron (1999, p. 307). 
planteamiento estoico 28 . La libertad y la felicidad se logran, en ambas éticas, a través del conocimiento de que la virtud consiste en vivir de acuerdo con la propia naturaleza, lo que entraña seguir los dictados de la recta razón y así adquirir conocimiento de Dios o la Naturaleza. La virtud así entendida, además, es sinónimo de felicidad. 29

Sin embargo, de nuevo encontramos aquí diferencias entre el planteamiento ético spinoziano y el estoico, que derivan de las distintas premisas ontológicas de las que parten. La cuestión es de nuevo cómo se entiende el conatus, o mejor la naturaleza, en esa ecuación entre la razón, la virtud y la felicidad, pues si ese término de la ecuación recibe un distinto significado en cada planteamiento, también se verán afectadas las similitudes que, según acabamos de argüir, existen entre la ética estoica y la spinoziana. En este sentido, hay un campo, el de la filosofía de las pasiones, en el que puede verse de forma más clara en qué sentido el planteamiento ético spinoziano se distancia del estoico.

\section{Páthos estoico y spinoziano}

En la filosofía de Spinoza la teoría de las pasiones funciona como un vínculo entre la ontología y la ética. En cierto sentido, también es así en el estoicismo. Hay ciertas premisas de la ontología que marcan el itinerario ético, y las pasiones están a medio camino entre una y otra. La reflexión sobre las pasiones enlaza con la antropología y es una parte de la ética ${ }^{30}$. Pero, ¿cómo conciben las pasiones los estoicos? ¿Estarían dispuestos a admitir, como señala Spinoza en el prólogo de la III parte de la Ética, que son cosas naturales que no se oponen a la razón? ¿O más bien la crítica que Spinoza dirige contra ciertos hombres excelentes que han errado en su noción y terapia de las pasiones se refiere al estoicismo?

\section{a) Concepción cognitiva y normativa de las pasiones}

En cuanto al carácter natural de las pasiones, la respuesta es controvertida. El estudio clásico de A. Long sobre el estoicismo no menciona el carácter natural o antinatural de las pasiones como un tópico del estoicismo. Si pensamos en Séneca, que como se ha señalado, es el estoico más citado por Spinoza, entonces la respues-

\footnotetext{
${ }^{28}$ En este sentido, Spinoza señala que "la virtud absoluta del alma es el conocimiento". E, IV, 28, dem. (Geb. II, 228) (315). Y al final de la Ética escribe: "la felicidad no es un premio que se otorga a la virtud, sino que es la virtud misma." E, V, 42 (Geb. II, 307) (427).

${ }^{29}$ Cf. Long (2003, p.13).

30 Long señala, en este sentido, que la división de la ética atribuida a Crisipo abarca tres grandes categorías: primera, "sobre el impulso"; segundo, "sobre los bienes y los males"; tercera, "sobre las pasiones” (Long 1977, p. 181).
} 
ta es negativa. Las pasiones no son algo natural porque no pertenecen de manera ineliminable a nuestra naturaleza31. Tampoco son algo natural en el sentido de que nuestra naturaleza nos pida mantenerlas o potenciarlas. Es más, el estoico sostiene que la propia naturaleza exige su eliminación. De este modo, incurre en el antinaturalismo que critica Spinoza en el prólogo 32 .

En lo que respecta a la racionalidad o irracionalidad de los afectos, la respuesta también es compleja, pues depende de lo que se entienda por racional, los estoicos estarían dispuestos o no a admitir que las pasiones son racionales. Y así, afirman que las pasiones son racionales en el sentido de que son juicios de la razón. Sin embargo, no reconocerían que son racionales en el sentido de que se adecuen a la recta razón, ya que las pasiones son juicios, pero falsos. La mayoría de los estoicos, así como una gran parte de la tradición griega antigua, mantiene una concepción cognitiva de las pasiones ${ }^{33}$. Las pasiones, afirma Crisipo, son juicios ${ }^{34}$. ¿Qué diría Spinoza de esto?

Spinoza define los afectos, tanto activos como pasivos, como afecciones del cuerpo, por las cuales aumenta o disminuye la potencia de obrar de ese cuerpo, y como ideas de esas afecciones ${ }^{35}$. La pasión es, pues, un tipo de afecto y, en cuanto tal, es una idea. Es cierto, sin embargo, que las pasiones no son ideas de la razón, sino ideas de la imaginación, aunque eso no implica que sean irracionales ${ }^{36}$. En cualquier caso, también Spinoza contempla el aspecto cognitivo de la pasión. Ahora bien, él muestra el aspecto corporal que, en igual medida que el mental, constituye la pasión. Spinoza reconoce, en mucha mayor medida que el estoicismo, la importancia del cuerpo para la filosofía, y en concreto para la reflexión sobre las pasiones, y lucha, de ese modo, contra el prejuicio espiritualista que ha dominado a gran parte de la tradición, y así, al estoicismo. Pero no sólo en este aspecto se separan el spinozismo y el estoicismo. También hay diferencias importantes en el carácter que ambos atribuyen a esos juicios o ideas que son las pasiones.

\footnotetext{
31 Véase a este respecto la Epístola 22 de Séneca. Allí el filósofo pone en boca de la naturaleza la siguiente afirmación: "¿Qué significa esto? Os engendré sin pasiones, sin temores, sin superstición, sin perfidia y sin los restantes vicios. Salid como habéis entrado" (Epistolas morales a Lucilio, III, Ep.22, 15).

32 En este sentido, Diógenes Laercio señala que "la pasión misma es, según Zenón, un movimiento irracional del alma en contra de la naturaleza, o un impulso excesivo." ( D.L., VII, 110).

33 Cf. Nussbaum (2003, p. 459).

34 "Ellos opinan que las pasiones son juicios (kríseis), según afirma Crisipo en su Sobre las pasiones. Por ejemplo, la avaricia es la suposición de que el dinero es bello, e igualmente la embriaguez, la incontinencia y las demás." (D. L., VII, 111).

35 Cf. E, III, def. III, (Geb. II, 139) (193).

36 Spinoza señala que "el alma está sujeta a tantas más pasiones cuantas más ideas inadecuadas tiene,y, por contra, obra tantas más cosas cuantas más ideas adecuadas tiene.” E, III, 1, corol. (Geb. II, 141) (195). Y las ideas inadecuadas, según explica el filósofo en el libro II de la Ética, pertenecen siempre al primer género de conocimiento, es decir, a la imaginación.
} 
Las creencias en las que consisten las pasiones son creencias valorativas, en concreto, son ideas que otorgan un alto valor a los objetos externos, que son vulnerables porque pueden verse afectados por lo que sucede en el mundo, y sobre los que no tenemos un control absoluto. Las creencias en las que consisten las pasiones "presuponen, pues, el carácter no autosuficiente de las cosas más valiosas (o de algunas de ellas)." 37 Ésta es una tesis que suscribe tanto el estoicismo como el spinozismo. Ambos mantienen una concepción cognitiva y normativa de las pasiones. Las pasiones son juicios o ideas valorativas. Ahora bien, el carácter de este aspecto cognitivo y normativo de la pasión es sólo débil para el estoico, mientras que para Spinoza es fuerte. La pregunta que hay que responder, llegados a este punto, es si los juicios que conceden un alto valor a los bienes externos, es decir, las pasiones, son verdaderos o falsos. El estoicismo argumenta a favor de la falsedad de esos juicios. Spinoza, en cambio, reconocerá, en cierta medida, su verdad. La cuestión reside, pues, en el distinto valor que los estoicos y Spinoza conceden a los bienes externos. A partir de aquí podemos comprender qué distancia separa la ética estoica de la spinoziana.

Para el estoico los bienes externos sólo tienen un valor instrumental. Pero son cosas que no tienen ningún poder para hacernos vivir feliz o desgraciadamente. ${ }^{38}$ Desde un punto de vista moral, no tienen, pues, ningún valor. Las ventajas naturales son indiferentes moralmente, aunque puedan ser preferibles. En el estoicismo más ortodoxo la persona virtuosa tiene dentro de sí todo lo que necesita. Se basta a sí misma, y por tanto, vive para sí, concentrada en sí misma. Séneca recoge la anécdota de Estilpón, quien, estando su patria sometida y sus hijos y mujer muertos, mientras escapaba de un incendio solo, y pese a todo, feliz, respondió a la pregunta de Demetrio sobre si había perdido alguna cosa, afirmando que todos sus bienes estaban con él, es decir, con él estaba la disposición a no considerar un bien nada que le pudiesen arrebatar. "Esta sentencia -observa Séneca- coincide con la del sabio estoico: también éste lleva por igual sus bienes intactos a través de ciudades incendiadas, ya que él se contenta consigo mismo; a este límite circunscribe su felicidad." 39

Sin embargo, Spinoza arguye que "nosotros no podemos prescindir de todo lo que nos es externo para conservar nuestro ser, y no podemos vivir sin tener algún comercio con las cosas que están fuera de nosotros; si, además, tomamos en consideración nuestra alma, vemos que nuestro entendimiento sería más imperfecto si el alma estuviera aislada y no supiese de nada que no fuera ella misma." 40 Nuestra

\footnotetext{
37 Nussbaum (2003, p. 460).

38 Véase a este respecto la distinción que establece Cicerón entre los aristotélicos y los estoicos en $\mathrm{Del}$ supremo bien y del supremo mal, III, 13, 43.

39 Epistolas morales a Lucilio, I, Ep. 9, 19.

40 E, IV, 18, schol. (Geb. II, 222-223) (306-307).
} 
naturaleza es relacional. Somos modos que necesitan encontrarse con otros modos para subsistir. Las relaciones con las cosas externas son necesarias y, en la mayoría de los casos, útiles. Hay muchas cosas fuera de nosotros que nos son útiles y que por ello han de ser apetecidas, esto es, juzgadas buenas ${ }^{41}$. Son cosas buenas, pues, y no sólo preferibles. Éste es el argumento y la tesis de Spinoza que no comparten los estoicos.

Spinoza señala que "servirse de las cosas y deleitarse con ellas cuanto sea posible (no hasta la saciedad pues eso no es deleitarse) es propio de un hombre sabio. Quiero decir que es propio de un hombre sabio reponer fuerzas y recrearse con alimentos y bebidas agradables, tomados con moderación, así como gustar de los perfumes, el encanto de las plantas verdeantes, el ornato, la música, los juegos que sirven de ejercicio físico, el teatro y otras cosas por el estilo, de que todos pueden servirse sin perjuicio ajeno alguno (...) Y así, esta norma de vida - concluye Spinozaconcuerda muy bien con nuestros principios y con la práctica común, por lo cual, si hay alguna regla de vida que sea la mejor, lo es ésta, así como la más recomendable en todos los sentidos" 42 . Este importante escolio de la proposición 45 del libro IV de la Ética confirma que los bienes externos sobre los que no tenemos control absoluto, esto es, las ventajas naturales y las pasiones asociadas con ellos, no sólo tienen un valor instrumental, sino que "son propias de un hombre sabio", es decir, son propias del virtuoso.

\section{b) ¿Extirpar las pasiones? El prefacio del libro V de la Ética}

En este sentido, podemos concluir ahora con mayores argumentos que para Spinoza las ideas valorativas con las que están comprometidas las pasiones, o al menos ciertas pasiones, no son necesariamente falsas, ya que conceden adecuadamente un alto valor a los bienes externos. E incluso no sólo es que las pasiones concedan adecuadamente valor, sino que ellas mismas son valores. Debido a la estructura reflexiva de la pasión, la mayoría de esos bienes externos a los que las pasiones otorgan una gran importancia, son pasiones ellos mismos. Sin pasión, o mejor, sin pasiones alegres, dirá Spinoza, ni siquiera la razón puede hacernos más libres, mejores y más felices. El conocimiento es necesario, pero no suficiente ${ }^{43}$. Razón y pasión deben trabajar juntas. Spinoza aboga por una fuerte concepción cognitiva y normativa de las pasiones. Ésta es la base desde la que elabora su crítica a la terapia de las pasiones estoica, tal y como ésta aparece en el prefacio del libro $\mathrm{V}$ de la Ética.

41 Ibid.

42 E, IV, 45, schol. (Geb. II, 244-245) (338).

43 Spinoza señala que "el conocimiento verdadero del bien y el mal, en cuanto verdadero, no puede reprimir ningún afecto. Ahora bien, en la medida en que es un afecto, sólo si es más fuerte que el afecto que ha de ser reprimido podrá reprimir dicho afecto.” E, IV, 14, dem. (Geb. II, 219) (302). 
"Aquí trataré, como he dicho, solamente de la potencia del alma, o sea, de la razón y mostraré ante todo la magnitud y características de su imperio sobre los afectos, en orden a regirlos y reprimirlos Ya hemos dicho más arriba que, desde luego, no tenemos un absoluto imperio sobre ellos. Sin embargo, los estoicos creyeron que los afectos dependen absolutamente de nuestra voluntad, y que podemos dominarlos completamente. Con todo, ante la voz de la experiencia, ya que no en virtud de sus principios, se vieron obligados a confesar que para reprimir y moderar los afectos se requiere no poco ejercicio y aplicación, y uno de ellos se esforzó por ilustrar dicha cuestión, si mal no recuerdo, con el ejemplo de los dos perros, uno doméstico y otro de caza: el repetido ejercicio acabó por conseguir que el doméstico se habituase a cazar y el de caza dejase de perseguir liebres. Dicha opinión está muy próxima a la de Descartes" 44.

La objeción que Spinoza expone es doble. En primer lugar, se critica, por imposible, la tesis estoica del poder absoluto que tenemos sobre las pasiones. Para Spinoza las pasiones forman parte de nuestra naturaleza de manera ineliminable. El hombre padece en la medida en que es una parte de la Naturaleza, que no puede concebirse por sí sola sin las demás partes. Y el caso es que no podemos dejar de ser una parte de la Naturaleza ${ }^{45}$. Necesitamos relacionarnos con otros modos para subsistir. Y en la medida en que permanecemos siempre afectados por causas exteriores, no podemos hacer desaparecer totalmente la tristeza. Ahora bien, estas necesarias relaciones con otros modos, esta condición nuestra de ser parte, puede ser fuente de padecimiento, pero también de alegría, esto es, también puede ser origen de valor. Y de este modo, la crítica a los estoicos no sólo se basa en la imposibilidad de su estrategia de trato con las pasiones. Las pasiones no sólo no pueden ser eliminadas, sino que, en el caso de las pasiones alegres, no deben serlo.

El otro objetivo de la crítica spinoziana, tal y como aparece en el prefacio, se refiere a la cuestión de la voluntad. B. Carnois señala que, según el estoicismo, el hombre tiene la facultad de no ceder a sus inclinaciones, salvo a aquellas que sabe que son conformes a su naturaleza. El ser humano es libre de elegir los objetos que le parecen susceptibles de satisfacer la tendencia fundamental de su ser a conservarse. Carnois se refiere entonces a la distinción estoica entre adpetitus, que es esta tendencia o deseo primitivo de conservar el ser, y adpetitio, que se refiere a los deseos particulares, esto es, al movimiento por el cual el hombre se vierte hacia un objeto determinado. Una cosa es, por tanto, la función constitutiva de la naturaleza misma del ser humano (adpetitus), y otra, el acto por el cual esta función se ejerce (adpetitio). Los estoicos sostienen que este último acto es libre ${ }^{46}$. Sin embargo, las divergencias entre el estoicismo y el spinozismo son aquí patentes. Para Spinoza nuestros

\footnotetext{
44 E, V, Praef. (Geb. II, 277-278) (383-384).

45 Cf. E, IV, 2 y 4 (Geb. II, 212) (291-292).

46 Cf. Carnois (1980, p. 260).
} 
deseos no dependen de nosotros, en el sentido en el que lo entienden los estoicos. El ser humano no tiene ningún poder de elegir los objetos de su deseo porque sus voliciones particulares son determinadas por la relación infinita de causas. "Todos nuestros esfuerzos o deseos se siguen de la necesidad de nuestra naturaleza."47

Además, en el prefacio del libro V de la Ética Spinoza podía haber objetado una tercera cosa al estoicismo. En este sentido, el reparo de Spinoza contra la propuesta estoica de liberarse de toda pasión, no implica una defensa del liberar toda pasión, sin ningún tipo de control, criterio o discernimiento. Spinoza insta a seleccionar aquellas pasiones que concuerdan con la razón, y a rechazar aquellas otras que no convienen con ella, es decir, insta a seleccionar y potenciar las pasiones alegres, y a valerse de la fuerza de éstas para combatir y reducir al mínimo posible las pasiones tristes. Spinoza realiza en su Ética toda una genealogía de las pasiones, mostrando que no todas tienen la misma categoría ontológica ni el mismo estatuto ético48. De este modo, la crítica de Spinoza al estoicismo podría haber tenido un tercer objeto: la tesis estoica de la unidad de las pasiones. ${ }^{49} \mathrm{Y}$ es que Spinoza enseña que quien no es capaz de ver el distinto ser y valor de cada una de las pasiones, no puede aprovechar la fuerza respectiva de cada cual, y por tanto, tampoco puede ser realmente libre, virtuoso y feliz. ¿Por qué? Porque sin pasión, es decir, sin finitud y sin vulnerabilidad, no hay valor posible.

Es cierto que, tal y como señala A. Long y R. Scottlaender, Spinoza no tenía un conocimiento pormenorizado de la doctrina estoica sobre las pasiones y se centra sólo en los aspectos más rigoristas de esa doctrina. 50 Sin embargo, la reflexión del estoicismo sobre las pasiones es muy rica y, sobre todo, fue evolucionando y matizándose con el tiempo. De este modo, desde el estoicismo medio de Panecio hasta el estoicismo tardío de Séneca se llevó a cabo una labor de flexibilización de la doctrina estoica, de modo que es este estoicismo menos ortodoxo el más afín a la filosofía de Spinoza. Y ello porque está dispuesto a considerar, al menos, la posibilidad de que ciertas pasiones pueden tener un valor ético, y quizá también cierto estatuto ontológico. En el estoicismo, al igual que ocurre en la obra de Spinoza, hay una evolución creciente hacia posiciones cada vez más coherentemente naturalistas.

De este modo, si nos centramos en el tema de las pasiones y, en concreto, en la relación que entraña con el modelo de sabiduría que ofrece el estoicismo, hay que

\footnotetext{
47 E, IV, Appendix, cap. I (Geb. II, 266) (367).

48 En este sentido, la distinción clave de la Ética es la distinción entre pasiones alegres y pasiones tristes. Cf. E, III, 11, schol. (Geb. II, 149) (207).

49 Como prueba de esta unidad de las pasiones puede verse el siguiente texto: "Otra de sus tesis es que los pecados son iguales, según dicen Crisipo en el libro cuarto de sus Investigaciones morales, y Perseo y Zenón. Pues como una verdad no lo es más que otra verdadera, y tampoco una mentira lo es más que otra mentira, así tampoco un engaño lo es más que otro engaño, ni un pecado más que otro pecado"(D.L., VII, 120). Esto mismo que se dice de los pecados y de la falsedad, puede decirse de las pasiones, ya que las pasiones son precisamente un tipo de juicios falsos.
}

50 Cf. Long (2003, pp. 27-28, nota 14) y Scottlaender (1986, p. 8). 
señalar que la imagen del sabio autosuficiente e incluso impasible, se fue matizando con el tiempo hasta el punto de que el estoicismo admitió que nuestro progreso moral venía no tanto tipificado por la extirpación de todos los afectos, sino por la ocurrencia de afecciones del alma, que son disposiciones de un principio-rector cada vez más consistente con la recta razón ${ }^{51}$. Los estoicos acentuaban la necesidad de resistir a las pasiones mórbidas. El sabio estoico, en este sentido, está libre de todas estas pasiones, esto es, de la ira, la ansiedad, la codicia, el miedo, la exaltación, etc.. Pero no es completamente impasible, contrariamente a la concepción popular del sabio estoico. Y ello porque el sabio tiene buenas afecciones del alma ${ }^{52}$. La benevolencia, el deseo de cosas buenas a favor de otro, la alegría, la complacencia en acciones virtuosas, pueden acompañar, pues, a la sabiduría 53 .

De este modo, este estoicismo menos ortodoxo es bastante afín a la filosofía de las pasiones spinoziana. Ambos planteamientos distinguen entre malas pasiones y buenas afecciones del alma y, además, coinciden al señalar qué tipo de pasiones y afecciones pertenecen a una y otra categoría. Destaca especialmente, en este sentido, la condena común del miedo y de la esperanza. En este sentido, es, de nuevo, el estoicismo de Séneca el que pudo tener mayor influencia sobre la filosofía de Spinoza. En De vita beata se afirma que el supremo bien está situado en un lugar donde no hay espacio ni para la esperanza ni para el miedo ${ }^{54}$. Una tesis similar defiende Spinoza en el Tratado Breve 55 .

51 Cf. SVF, III, 617 y 625; Long (1977, pp. 199-200).

52 "Afirman también que hay tres afecciones buenas del ánimo: la alegría, la cautela y la decisión. Así la alegría es contraria, dicen, al placer, siendo una exaltación razonable. La cautela es contraria al temor, siendo una precaución razonable. Pues el sabio de ningún modo se amedrentará, sino que se mostrará cauto. Afirman que la decisión, que es una tendencia razonable, es contraria al deseo. Así como algunas pasiones quedan subordinadas a las primarias, de la misma manera algunas lo están también a las afecciones buenas primarias. Así, bajo la decisión caen la benevolencia, la amabilidad, el respeto y el afecto; bajo la cautela, la reverencia y la modestia; bajo la alegría, el gozo, el contento y el buen humor." (D. L., VII, 116). Optamos aquí por traducir el término eupátheia por buena afección del ánimo, tal y como propone Carlos García Gual en la edición castellana de la Vida de los filósofos de Diógenes Laercio. Y ello porque creemos que con esta traducción se expresa con mayor claridad que los estoicos no se referían con este término ni a las pasiones que, en general, se consideraron siempre malas, ni a los afectos activos racionales a los que se refiere Spinoza.

53 Cf. Long (1977, pp. 201-201). Long se refiere a Séneca, Epistolas morales a Lucilio, III, Ep. 23, 2-3. 54 También en la Epístola 14 Séneca, en referencia a Hecatón, moralista del estoicismo medio, muestra que la esperanza y el miedo, indisolublemente ligados, han de ser rechazados. "Mas voy a compartir contigo también el pequeño lucro de este día. He hallado en los escritos de nuestro Hecatón que la supresión de los deseos aprovecha a la par como remedio del temor. Afirma: Si dejas de esperar, dejarás de temer”. Me objetarás: ¿Cómo sentimientos tan dispares corren parejos?” Así es, querido Lucilio; aunque parezcan ser contradictorios, van unidos. Igual que una misma cadena une al preso y al soldado que lo guarda, así esos sentimientos que son tan diferentes marchan a la par: el miedo sigue a la esperanza."(Epístolas morales a Lucilio, I, Ep. 5, 7). Cf. Scottlaender (1986, p. 4) y Lagrée (2004, pp. 87-88). 55 Spinoza señala allí que el miedo y la esperanza "presuponen cosas a las que no debemos adherirnos a consecuencia de su naturaleza variable" Tratado Breve, II, 9 (Geb.,I, 71-72 ) ( 121-122). 
Estas afirmaciones muestran que el estoicismo matizó su posición con respecto a las pasiones hasta el punto de distinguir entre las malas pasiones y las buenas afecciones del alma. No obstante, no parece que haya indicios de que la eupátheia estoica pueda interpretarse en el sentido del afecto activo spinoziano. No hay, pues, ni siquiera en el estoicismo menos ortodoxo, algo equivalente a la distinción spinoziana entre afectos pasivos o pasiones y afectos activos racionales. De hecho, ésta es una distinción que sólo aparece muy tardíamente en la obra de Spinoza.

En definitiva, a pesar de estas afinidades entre el último estoicismo, menos radical, y la filosofía de Spinoza, es cierto que en ésta hay, en general, una valoración más positiva de las pasiones. B. Carnois señala esta tesis a propósito del deseo. En la filosofía de Spinoza, según nos explica, los deseos llamados pasiones son buenos o malos según nazcan de afecciones buenas o malas. Esta distinción spinoziana parece, en principio, retomar la distinción estoica entre la buena afección del alma (eupátheia) y la pasión (páthos=páthēma). Sin embargo, para el estoicismo las pasiones son siempre malas y contra naturaleza, mientras que para Spinoza los deseos llamados pasiones son naturales y pueden ser tanto buenos como malos ${ }^{56}$. También M. Pohlenz, en su monografía sobre la influencia del estoicismo, señala que en la Modernidad y, en concreto, en la filosofía de Spinoza hay una valoración más positiva de las pasiones, aunque insiste igualmente en aquellos principios estoicos que perviven en la filosofía moderna. ${ }^{57} \mathrm{M}$. Vegetti, en esta misma línea de interpretación, señala que en el estoicismo hay una noción más negativa de la pasión como enfermedad. 58

\section{Balance: naturalismo estoico y spinoziano}

El propósito de este estudio residía en mostrar por una parte, que el estoicismo es una de las fuentes principales del naturalismo de Spinoza, y, por otra, que, sin embargo, hay diferencias en el carácter, el alcance o nivel de desarrollo del naturalismo estoico y del naturalismo spinoziano. Estas diferencias son más manifiestas en la filosofía de las pasiones que ambos propusieron. La cuestión estriba, una vez más, en el diferente concepto de naturaleza que ambos tienen. Para Spinoza nuestra naturaleza está hecha no sólo de razones, sino también de pasiones, mientras que para el estoico no, o, al menos, no del mismo modo. El sabio estoico se caracteriza por su autosuficiencia y por su ausencia de pasiones. Sin embargo, tal y como se acaba de señalar, este tópico del estoicismo más ortodoxo se fue matizando con el tiempo, hasta el punto de que los estoicos reconocieron que el sabio no se define por

56 Cf. Carnois (1980, p. 268).

57 Cf. Pohlenz (2005, p. 988).

58 Cf. Vegetti (1998, p. 86). 
su insensibilidad sino por tener buenas afecciones que son consistentes con la razón. También el estoicismo, como la propia filosofía de Spinoza, va evolucionado hacia posiciones cada vez más naturalistas. Hay, pues, un momento en el que la afinidad entre ellas es grande. De este modo, no parece arriesgado afirmar que el estoicismo tardío tuvo una importante influencia en las obras de juventud de Spinoza. Hay algunos paralelismos y préstamos entre las primeras obras de Spinoza y las tesis propias del estoicismo más tardío de Séneca ${ }^{59}$.

Sin embargo, la filosofía de Spinoza fue evolucionando hacia posiciones más plenamente naturalistas, de modo que la Ética marcaba ya una distancia mayor con respecto a este estoicismo menos radical. En esta obra podemos encontrar ya la filosofía más genuina y original de Spinoza. Su naturalismo está más desarrollado. En ella se concede a las pasiones una categoría ontológica y un valor ético mayor que el que está dispuesto a conceder el estoico menos ortodoxo que podamos imaginar. De este modo, la mayoría de los intérpretes coinciden en poner de manifiesto que, a pesar de que los estoicos distinguieran la eupátheia de la pasión mórbida, y reconocieran que la sabiduría puede ir acompañada de estas buenas afecciones, la valoración de las pasiones por parte de Spinoza es más positiva. Y ello porque en la Ética se demuestra, en un sentido más radical que el que pudieron pensar los estoicos, que sin finitud, es decir, sin vulnerabilidad, sin padecimiento, y, en definitiva, sin pasión, no hay valor posible. Por eso Spinoza señala que la Naturaleza, que es infinita e impasible, es también amoral. Por eso sólo para aquellos seres de condición intermedia, entre la infinitud de la Sustancia y la estupidez de las bestias, es posible la moral. Sólo el hombre, cuya naturaleza está siempre transida de pasiones y de razones, puede llegar a ser feliz, si es capaz de valerse de la fuerza de las pasiones alegres y de la lucidez de la razón para restar poder a sus tristezas. De este modo, el carácter del naturalismo spinoziano es, además, mucho más jovial que el del estoico. Estar alegre es una condición de posibilidad de la virtud, felicidad y libertad spinozistas.

Y a pesar de las diferencias, queremos finalizar volviendo a poner de manifiesto lo que para nosotros es una afinidad fundamental entre ambas filosofias: su naturalismo. En ese sentido, un estudio que, como el nuestro, se proponga determinar cuáles son las fuentes clásicas del naturalismo spinoziano debe tener en cuenta al estoicismo como una de sus principales fuentes. La asimilación que ambos plantearon entre Dios y la Naturaleza, y su defensa de la inmanencia, son muestra de la actitud naturalista propia de su pensamiento. Desde esta ontología naturalista pensaron la ética, de forma que en la naturaleza hallaron uno de los pilares fundamentales de sus respectivas propuestas morales. Ni el estoicismo, ni el spinozismo necesitaron apelar a instancia trascendente alguna para pensar la virtud, la felicidad y la

59 Véase, en este sentido, el interesante trabajo de Proietti (1989) sobre la influencia de las Epistolas morales a Lucilio en el Tratado de la reforma del entendimiento de Spinoza. 
libertad. De este modo, el fondo naturalista común que Spinoza comparte con el estoicismo hace que su pensamiento esté mucho más próximo a las tesis estoicas y, en general, al pensamiento antiguo greco-romano, que a las filosofías de la trascendencia, de carácter judeo-cristiano que, sin embargo, Spinoza conocía mucho mejor 60 .

Esta filiación la deja patente el propio Spinoza en la carta que le dirige a $\mathrm{H}$. Oldenburg en 1675. Spinoza se expresa así sobre lo que él considera algunos puntos fundamentales de su filosofía. "Respecto al primero- escribe- a saber, Dios y la Naturaleza, sostengo una opinión muy distinta de aquella que suelen defender los modernos cristianos. Afirmo, en efecto, que Dios es causa inmanente, como se dice, de todas las cosas y no transitiva; aun más, que todas las cosas están en Dios y se mueven en Dios, lo afirmo yo con Pablo y quizá también, aunque de otro modo, con todos los antiguos filósofos e incluso, me atrevería a decir, con todos los antiguos hebreos, en cuanto se puede colegir de algunas tradiciones antiguas, pese a sus adulteraciones sin número." 61

\section{Referencias bibliográficas}

\section{Fuentes primarias}

Cicerón (1999): Sobre la naturaleza de los dioses, trad. A. Escobar, Madrid, Gredos.

CiCERÓn (2007): Del supremo bien y del supremo mal, trad. V. J. Herrero Llorente, Madrid, Gredos.

Laercio, D. (2008): Vidas de los filósofos ilustres, trad. C. García Gual, Madrid, Alianza.

Epicteto (1999): Manual, trad. J. M. García de la Mora, Barcelona, Anthropos. Plinio El Viejo (1995): Historia natural, vol. I., trad. A. Fontán, A. Moure Casas y otros, Madrid, Gredos.

SÉNECA (1989): Epistolas morales a Lucilio, vol. II, trad. I. Roca, Madrid, Gredos. SÉNECA (1994): Epistolas morales a Lucilio, vol. I, trad. I. Roca, Madrid, Gredos. SÉNECA (2000): De la cólera, trad. E. Otón Sobrino, Madrid, Alianza.

60 Prueba de ello son las dificultades comunes que tanto el estoicismo como el spinozismo tuvieron para expresarse en épocas en las que imperaban las filosofías de la trascendencia. A. Long señala, en este sentido, que el estoicismo era pagano y el cristianismo aborrecía lo pagano. Y ello aunque el cristianismo pretendiera extraer del estoicismo aquellos preceptos sobre el deber y la humanidad que le parecían innegables. (cf. Long 1977, p. 111). En cuanto a Spinoza, para comprender cómo el cristianismo interpretó el spinozismo y por qué entre ellos nunca hubo una buena sintonía, puede verse la carta que dirige A. Burgh a Spinoza en septiembre de 1675. Cf. Ep. 67 (Geb. IV, 285) (359).

61 Ep. 73 (Geb. IV, 307) (387). 
SpInozA, B. (1972): Spinoza Opera, Herausgegeben von Carl Gebhardt, Heidelberg, Carl Winters Universitätsverlag (4 vols.).

SpinozA, B. (1988): Correspondencia, trad. A. Domínguez, Madrid, Alianza Editorial.

SpinozA, B. (1990): Tratado Breve, trad. A. Domínguez, Madrid, Alianza Editorial.

SpINozA, B. (2003): Tratado teológico-político, trad. A. Domínguez, Madrid, Alianza Editorial.

SpinOzA, B. (2004): Tratado político, trad. A. Domínguez, Madrid, Alianza Editorial.

SpINOZA, B. (2006a): Ética demostrada según el orden geométrico, trad. V. Peña, Madrid, Alianza Editorial.

SpinozA, B. (2006b): Tratado de la reforma del entendimiento, trad. A. Domínguez, Madrid, Alianza Editorial.

SpinozA, B. (1924): Stoicorum Veterum Fragmenta, ed. H. von Arnim, Leipzig (4 vols.)

\section{Fuentes secundarias}

Carnois, B. (1980) : "Le désir selon les Stoïciens et selon Spinoza", Dialogue. Canadian Philosophical Review, 19, Cahier 2, pp.255-277.

Deleuze, G. (1971): Lógica del sentido, trad. A. Abad, Barcelona, Seix Barral.

Ferrater Mora, J. (1994): Diccionario de filosofia, Barcelona, 1ªed. revisada y actualizada en Ariel Referencia.

JAmES, S. (1993): "Spinoza the Stoic", en T. Sorrell (ed.), The Rise of Modern Philosophy. The Tension between the New and Tradicional Philosophies from Machiavelli to Leibniz, Oxford, Clarendon Press, pp. 289-316.

Lagree, J. (2004) : Spinoza et le débat religieux. Lectures du Traité théologicopolitique, Rennes, Presses Universitaires de Rennes.

Long, A. (1977): Filosofía helenistica. Estoicos, epicúreos, escépticos, trad. P. Jordan de Urries, Madrid, Biblioteca de la Revista de Occidente.

Long, A. (2003): "Stoicism in the Philosophical Tradition. Spinoza, Lipsius, Butler" en J. Miller / B. Inwood (eds), Hellenistic and early modern philosophy, Cambridge, Cambridge University Press, pp. 7-29.

Long, A. / Sedley, D. N. (1988): The Hellenistic philosophers, Cambridge, Cambridge University Press (2 vols).

Matheron, A. (1999) : "Le moment stoïcien de l'Étique de Spinoza", en P.-F. Moreau (dir.), Le retour des philosophies antiques à l'âge classique. Le stoïcisme au XVIe et au XVIIe siècle. Vol. I., Paris, Bibliothèque Albin Michel Idées, pp. 302-316.

Nussbaum, M. C. (2003) : La terapia del deseo. Teoría y práctica en la ética helenistica, trad. M. Candel, Barcelona, Paidós. 
Pohlenz, M. (2005): La Stoa: storia di un movimento spirituale, trad. O. De Gregorio, Milán, Bompiani.

Proietti, O. (1989) : "Lettres à Lucilius. Une source du De Intellectus Emendatione de Spinoza", Lire et traduire Spinoza. Travaux et documents du Groupe de recherches spinozistes. Vol. I, Paris, Presses d'1'Université de Paris-Sorbonne, pp. 39-59.

Scottlaender, R. (1986) : "Spinoza et le stoïcisme”, Bulletin de l'Association des Amis de Spinoza, 17, pp. 1-8.

SEverac, P. (1996) : “Convenir avec soi, convenir avec autrui: Éthique stoïcienne et éthique spinoziste", Studia spinozana, 12 , pp. 105-119.

Vegetti, M. (1998): "Pasiones antiguas: el yo colérico", en S. Vegetti Finzi (comp.), Historia de las pasiones, trad. A. Bonanno, Buenos Aires, Losada, pp. 61-96.

Inmaculada Hoyos Sánchez

Departamento de Filosofía II: Filosofía

Universidad de Granada

ihoyos@ugr.es 